\title{
Resenha: Faxinal Taquari dos Ribeiros: diálogos interdisciplinares, sustentabilidade e etnoecologia
}

\author{
Revisión: Faxinal Taquari dos Ribeiros: diálogos \\ interdisciplinarios, sostenibilidad y etnoecología
}

\section{Review: Faxinal Taquari dos Ribeiros: interdisciplinary dialogues, sustainability, and ethnoecology}

\author{
CARVALHO, Silvia Méri; FLORIANI, Nicolas (Organizadores). \\ Ponta Grossa: Editora UEPG, 2017. 264p. il.
}

Melissa Koch Fernandes de Souza Nogueira melissaknog@yahoo.com.br Universidade Estadual de Ponta Grossa, UEPG, Ponta Grossa, PR.

A publicação Faxinal Taquari dos Ribeiros: diálogos interdisciplinares, sustentabilidade e etnoecologia, publicada em 2017, com caráter multidisciplinar, foi elaborada por 17 autores de diferentes áreas: Geografia, Engenharia Florestal, Ciências Biológicas, Engenharia Agronômica e Zootecnia. O livro pretende apresentar os resultados de projetos de pesquisa da Rede Faxinal Pesquisa, que visam à reflexão acadêmica acerca das comunidades tradicionais faxinalenses na Floresta com Araucária, em especial do Faxinal Taquari dos Ribeiros, localizado no município de Rio Azul, na região Centro-Sul do estado do Paraná. Com o objetivo de "avaliar a sustentabilidade socioambiental desse sistema faxinal", refletindo sobre as práticas e os saberes populares da natureza, a obra destina-se ao leitor interessado na territorialidade faxinalense do povo rural

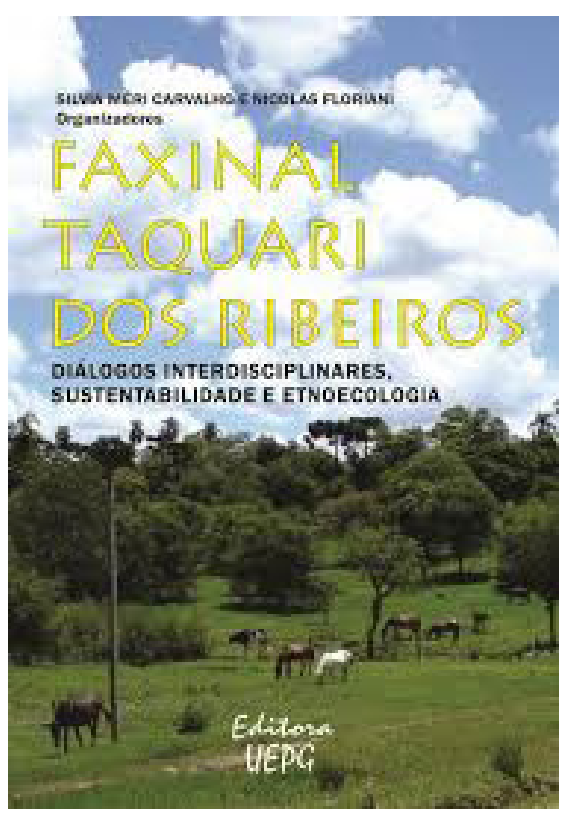
paranaense, com o enriquecimento científico de linguagem didática acessível, sendo inspiradora ao conhecimento do patrimônio histórico e cultural faxinalense.

A obra foi organizada em três seções e 11 capítulos, dividida de maneira a apresentar os aspectos biofísicos, do etnoconhecimento e da agrodiversidade do sistema faxinal, além de apresentar três estudos de caso, tendo como tema integrador a cultura e o saber faxinalense. 
A Seção I, composta por quatro capítulos, possibilita o entendimento da relação entre a comunidade e seu território, a partir do entendimento das práticas físico-naturais e culturais realizadas pela comunidade. Edson Struminski (in memorian) e Juliano Strachulski apresentam no capítulo 1 - A evolução da vegetação do Faxinal Taquari dos Ribeiros. Os autores abordam aspectos da vegetação em termos fisionômicos e ecológicos num diagnóstico da dinâmica da fragmentação das áreas florestais do faxinal para entender a dinâmica florestal local e sua sustentabilidade. Através da uma análise temporal comparando dados de 1980 e 2011, o estudo sugere que uma lenta degradação da área florestal.

Na sequência, no capítulo 2, Rosemeri S. Moro, Marcel Comin, Tiaro K. Pereira, Tiemi A. de França Sakano e Neuri C. Machado levantam em Estrutura da vegetação arbórea no Criadouro Comum, os atributos do estrato arbóreo-arbustivo e concluem que, mesmo evidenciados impactos do manejo sobre a área, trata-se de um remanescente significativo de Floresta Ombrófila Mista, e ressaltam a importância de sua conservação no contexto do Bioma Mata Atlântica.

No capítulo 3, Nicolas Floriani e Maria Ligia C. Pinto analisam o tema Os Solos das Terras de Plantar e do Criadouro Comunitário do Faxinal Taquari dos Ribeiros: mapeamento e diagnóstico, onde ilustram detalhadamente os resultados do levantamento e mapeamento pedológico em topossequências, assim como dados físico-químicos dos solos nas áreas florestal e de cultivo no faxinal.

Finalmente, no capítulo 4 - Uso e ocupação da terra no Sistema Faxinal Taquari dos Ribeiros, Rio Azul (PR), Entre 1980 e 2008, Camila Bittencourt Silva e Silvia Méri Carvalho buscam entender as mudanças do sistema faxinal em relação à dinâmica do uso da terra, verificando a conexão entre as transformações ocorridas no uso, como a modernização da agricultura representada aqui pela inserção da fumicultura.

A Seção II, voltada para a compreensão da representação de seu território pelos agricultores, é composta por mais quatro capítulos. Nicolas Floriani e Juliano Strachulski apresentam no capítulo 5 - Mapeamento e classificação etnopedológicos das Terras de Plantar: imaginário de fertilidade das Terras no Faxinal Taquari dos Ribeiros, elementos relativos à fertilidade das terras e sua gestão. Os autores inferem que o imaginário sobre a fertilidade no faxinal adquire novos sentidos conforme mudanças no contexto social, cultural e ambiental, tanto o concebido quanto o praticado. Apresentam ainda a hipótese de que ocorre adaptação, e não substituição, das práticas da agricultura moderna pelos agricultores faxinalenses.

Já no capítulo 6 - A Etnobotânica das plantas indicadoras da qualidade das terras do subsistema faxinalense 'Terras de Plantar', Juliano Strachulski e Nicolas Floriani tratam das experiências dos agricultores em relação a ecologia das plantas e sua relação com a qualidade das terras de plantar, demostrando o saber popular territorial de sua paisagem.

Olivier F. Vilpoux, em O papel das instituições formais e informais no Faxinal Taquari dos Ribeiros (capítulo 7), identifica os fatores que ameaçam a manutenção dos faxinais, tendo como foco 'criadouro', área de livre pastagem. O autor concluiu que a dissolução das instituições informais enfraquece o relacionamento entre os habitantes da comunidade, principalmente a relação entre os jovens com os mais experientes. Aponta também 
que as regras institucionais baseadas na preservação do criadouro estão enfraquecidas, fragilizando assim a manutenção do sistema faxinal.

Finalmente, no capítulo 8, Simone Fernandes e Silvia Méri Carvalho retratam A oficina participativa como instrumento para o diálogo de saberes na comunidade faxinalense Taquari dos Ribeiros em Rio Azul/PR, como forma de aumentar a participação da comunidade no processo de gestão e decisões referentes às estratégias para a sustentabilidade socioambiental do território faxinalense.

A Seção III consta de três capítulos voltados para os estudos de caso. No capítulo 9, Margit Hauer apresenta em O Papel de uma Área Especial de Uso Regulamentado para a valorização da sociobiodiversidade: o caso do Faxinal Taquari dos Ribeiros, as políticas públicas voltadas à conservação ambiental do território faxinalense do estado do Paraná, em especial o ICMS ecológico, que prevê a conservação da floresta nativa para recebimento local de recursos financeiros.

Em Uso e manejo dos recursos agroflorestais no Faxinal Taquari dos Ribeiros, Rio Azul/ PR (capítulo 10), Gabriela Schmitz Gomes, Margit Hauer e Maria Cristina M. Mazza, na perspectiva da valorização do sistema agroflorestal, apontam estratégias alternativas de uso e manejo multidisciplinares, preservando a base da cultura do território faxinalense

Ao final, Denyse M. Galvão Leite, no capítulo 11 - Criação de animais domésticos no Faxinal Taquari dos Ribeiros aborda os cuidados fitossanitários, nutricional e de manejo reprodutivo de animais soltos, preservando e estimulando a capacidade de pastejo das terras do 'criadouro' e as áreas conjugadas para a produção agrícola, as "terras de plantar".

O livro é de leitura agradável e enriquecedora, onde os organizadores e autores de cada capítulo entrelaçaram de forma admirável o conhecimento científico ao saber vernacular, deixando uma marca literalmente impressa da coexistência entre academia e sociedade. 